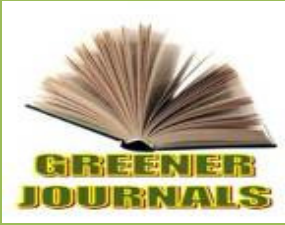

\title{
Comparative Study of some Cultivars of Rice (Oryza sativa L.) for Iron Fe Biofortification under Saline Condition
}

\section{${ }^{1 *}$ Ikuli Josiah M., ${ }^{1}$ Akonye Love A. and ${ }^{2}$ Efisue Andrew A.}

\author{
${ }^{1 *}$ Department of Plant Science and Biotechnology, University of Port Harcourt. \\ ${ }^{1}$ Department of Plant Science and Biotechnology, University of Port Harcourt. \\ ${ }^{2}$ Crop and Soil Science Department, University of Port Harcourt.
}

Article No.: 061117073

DOI: 10.15580/GJAS.2017.4.061117073

Submitted: 11/06/2017

Accepted: 16/06/2017

Published: 27/06/2017

${ }^{*}$ Corresponding Author

Ikuli Josiah $M$.

E-mail: ikulijosiah@yahoo.com

\section{Keywords:}

Fortified saline, Fe solution, Biofortification, rice and cultivars
Rice is a stable food crop in Nigeria and greater percentage of the world. Rice is an important cereal crop of the world and nutritionally potential food crop. Iron plays a vital role in human life. Such as in production of red blood cells, transportation of oxygen around the body, strong immune system and a component structure of the human haemoglobin. It is also involved in the conversion of blood sugar to energy. The study screened some cultivars of Oryza sativa for their abilities to retain Iron (Fe), their response to Fe biofortification and their adaptabilities and tolerance capacities for Fe biofortification under saline condition. Five (5) cultivars of lowland rice namely; FARO 44, UPIA 3, FARO 52,

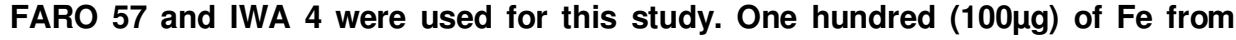
$\mathrm{FeNH}_{4} .\left(\mathrm{SO}_{4}\right) \cdot 12 \mathrm{H}_{2} \mathrm{O}$ was applied through foliar application. The $\mathrm{Fe}$ increase available for human body use was comparatively higher in the fortified than unfortified treatment, especially those planted in the non saline treated soil. Under saline condition, the Fe increase in fortified FARO 44 was less than in the unfortified by approximately nine percent (9.29\%). UPIA 3 was higher by $20.48 \%$, FARO 52 higher by $14.43 \%$, FARO 57 higher by $22.83 \%$ and IWA 4 was higher by $27.08 \%$. In the non saline fortified, FARO 44 was higher than the unfortified by $71.9 \%$, UPIA 3 by $20.26 \%$, FARO 52 by $30.71 \%$, FARO 57 was higher by $217.21 \%$ and IWA 4 increased by $6.95 \%$. The study revealed that FARO 57 was more sensitive to salinity in Fe biofortification and UPIA 3 was more suitable for Fe biofortification under saline condition among the cultivars used for the study. UPIA 3 is the best because it was more stable in both saline and non saline, fortified and unfortified conditions, high yielding and was not infected or being susceptible to any disease. The study also showed that FARO 57 in non saline soil had the best ability to retain $\mathrm{Fe}$ in iron biofortification. But unfortunately, FARO 57 has lodging mechanism that affected its yield.To eliminate micronutrients malnutrition and improve food security, there should be integration of multidiscipline and biofortification employed as a tool to produce cultivars of high yielding and rich in essential nutrients. 


\section{INTRODUCTION}

The most essential needs of human beings are food, Shelter and good health. Food security is the process whereby everyone has access to sufficient food quantity at all times, safe, nutritious food to maintain a healthy and active life and at affordable price (WHO, 1996).

To meet the demands of the geometric growing population of the world, the production of certain cereals food crops were intensified and one of them is rice. Unfortunately, the breeders concentrated only on yield and profitability to farmers when breeding these cultivars and do not put into consideration the consequences and availability of micronutrients which are essential for body regulation, building and other important functions in human. Lack of these nutrients leads to high micronutrients malnutrition in human especially the resource-poor families in the developing countries. Fe deficiency alone has been reported to have affected about two billion people (WHO and FAO, 2003). Deficiencies of various micronutrients including vitamin A, zinc and iron are common in the developing countries and affect billions of people. These can lead to among other symptoms a higher incidence of blindness; a weaker immune system, stunted growth and impaired cognitive development. According to Kennedy et al, (2003), humans require at least 44 known nutrients in adequate amounts and consistently to live healthy and productive lives. Iron (Fe), I, Zn, and Vitamin A deficiencies are the most prevalent among the deficient micronutrients (Kennedy et al., 2003). More than five million childhood deaths occur worldwide from micronutrients malnutrition every year (Anonymous, 2007).

The rural poor people tend to subsist on a diet of staple crops such as rice, wheat and maize which are low in these micronutrients and most cannot afford or efficiently cultivate enough fruits, vegetables or meat product that are necessary to obtain healthy levels of these nutrients. Iron is one of the three micronutrients (i.e. Fe, $\mathrm{Zn}$ and Vitamin A) that are recognised by the World Health Organisation (WHO) as limiting (OrtizMonasterior et al., 2007). Iron (Fe) plays a vital role in human life, some of which include: transportation of oxygen around the body, component structure of the human haemoglobin and for strong immune system, $\mathrm{Fe}$ played important role in the production of enzymes which had a vital role in the production of new cells, amino acids hormones and neurotransmitters. It is also involved in the conversion of blood sugar to energy (Nelson, 2014). World Health Organisation (WHO) estimated that, Fe biofortification could help in curing the 2 billion people suffering from iron deficiency- induced anaemia (Anonymous, 2008).

Rice is a staple food crop in Nigeria and greater percentage of the world. Rice is an important cereal of the world and a nutritionally potential food crop. Population increase in the world has reduced the available land for agricultural production. The cultivation of swamp rice is favoured with vas land area in the mangrove ecology. Unfortunately, salinity, Al, Fe toxicity and other environmental factors affect rice productivity in the mangrove environment. Hence the need to improve cultivars of high Fe concentration and tolerant to salinity to eliminate Fe malnutrition among people who consume mainly cereals and improve food security. To improve productivity and sustainable level of bioavailable iron, it is therefore necessary to screen the cultivars used by the farmers in order to identify cultivars that can tolerate salinity, adapt to the mangrove ecology and with the ability of retaining appreciable level of iron. This will provide a judicious utilisation of the available vas land area in the mangrove environment for good and healthy food production and food security.

The objective of this experiment is to study the response of Oryza sativa cultivars to Fe biofortification, their adaptability and tolerance ability under saline condition.

\section{MATERIALS AND METHODS}

The research was carried out at University of Port Harcourt Agricultural Research Green/Screen House, opposite School of Basic Studies University of Port Harcourt, Port Harcourt, Rivers State. (Lat. $4^{0} 65^{1} \mathrm{~N}$; Long. $7^{\circ} 05^{1} \mathrm{E}$ ). With a temperature range from $23^{\circ} \mathrm{C}$ to $35^{\circ} \mathrm{C}$ and total Rainfall range of $2000-3000 \mathrm{~mm}$ per anum, from August 2013 to June 2014.

\section{PLANTING MATERIALS AND PLANTING}

Rice (Oryza sativa L.) cultivars were obtained from AGRA-Germplasm, University of Port Harcourt in Port Harcourt, namely; UPIA 3, IWA 4, FARO 44, FARO 52 and FARO 57. Seedlings were transplanted 8 days after germination into the arranged pots at two seedlings per pot.

\section{FERTILIZER APPLICATION}

The fertilizers used (NPK 15:15:15) and Urea were obtained from Rivers State Agricultural Development Programme (ADP) Rumuodomaya, Port Harcourt.

Three grams $(3.0 \mathrm{~g})$ of NP K 15:15:15 was applied a week after transplanting (15 days after germination), as a basal application to each pot. At four weeks after transplanting, three grams $(3.0 \mathrm{~g})$ of Urea was also applied as split to each of the pot. Eight weeks after transplanting, three grams (3.0g) of N P K 15:15:15 and two grams $(2.0 \mathrm{~g})$ of Urea were applied to each pot.

\section{TREATMENT MATERIALS}


Ferric Ammonium (FeNH $4 .\left(\mathrm{SO}_{4}\right) \cdot 12 \mathrm{H}_{2} \mathrm{O}$, Nitric acid, $\mathrm{HCL}$ and $\mathrm{NaCl}$ were obtained from Bernaco Nigeria Limited Alakahia, Port Harcourt.

\section{SALINITY TREATMENT}

The method of Havlin et al, 2006, was adopted using the formula; Total dissolved salt (ppm or $\mathrm{mg} / \mathrm{L})=640 \times \mathrm{EC}_{\text {se, }}$, where $\mathrm{EC}_{\mathrm{se}}$ is the Electrical Conductivity of saturated extracts.

Therefore, to obtain $\mathrm{EC}_{\mathrm{se}}$ of $5 \mathrm{mmhos} / \mathrm{cm}$; $3200 \mathrm{mg}=5 \mathrm{EC}_{\text {se }}=(640 \times 5)$ of $\mathrm{NaCl}$ was dissolved in one litre of deionized water. This is equivalent to $5000 \mu \mathrm{S} / \mathrm{cm}$. This solution was used as treatment (stock solution).

Four (4) litres of the stock solution was used to wet potted soil $(15 \mathrm{~kg})$ as salinity treatments.

To maintain the salinity level, subsequently, $220 \mathrm{ml}$ of the stock solution was used to top up the treatments. This was done twice a week. Whenever rainfall diluted the soil in the saline treatments the application frequency was increased to four times a week.

\section{BIOFORTIFICATION}

The Enhanced Fertilizer Method was used for the biofortification. This is the process whereby micronutrients fertilizers are applied either through foliar or soil application to increase the nutrients biologically in plants or food crops.

\section{Preparation of Fortifying Solution}

a. The FAO/WHO method of Iron standard solution preparation was adopted. The Ferric ammonium $\left(\mathrm{FeNH}_{4} .\left(\mathrm{SO}_{4}\right) .12 \mathrm{H}_{2} \mathrm{O}\right)$ used as the Fe fertilizer was diluted to $100 \mu \mathrm{g}$ of $\mathrm{Fe}$ concentration fortifying solution was prepared according to the following steps.

i. The glassware was treated with $\mathrm{HCl}$ to remove all traces of iron on it.

ii. Ferric ammonium $\left(\mathrm{FeNH}_{4}\right.$. $\left.\left(\mathrm{SO}_{4}\right) \cdot 12 \mathrm{H}_{2} \mathrm{O}\right)$ weighing $8.63 \mathrm{~g}$ was added into $1000 \mathrm{ml}$ volumetric flask and dissolve in $20 \mathrm{ml}$ of diluted nitric acid and deionized water was added to $1000 \mathrm{ml}$ mark. iii. Ten $\mathrm{ml}(10 \mathrm{ml})$ of the solution was measured into $20 \mathrm{ml}$ of diluted nitric acid in $1000 \mathrm{ml}$ volumetric flask and deionized water was added to $1000 \mathrm{ml}$ mark making a concentration of $1.00 \mathrm{ml}=10 \mu$ Fe.

iv. Thereafter, $20 \mathrm{ml}$ of the iron solution from step 111 was pipette into $2000 \mathrm{ml}$ Erlenmeyer flask and distilled water was added to the $2000 \mathrm{ml}$ mark. Fe concentration $=100 \mu \mathrm{g}$.

\section{BIOFORTIFICATION APPLICATION}

The solution of Fe $(100 \mu \mathrm{g})$ diluted in step IV was applied through foliar application. Hand sprayer was used for this purpose. Application was done twice at a week interval on each of the varieties. It was applied at the booting and heading stage of the rice plant development.

\section{IRON (Fe) ANALYSIS}

Thirty grams $(30 \mathrm{~g})$ of seeds from each replicate were measured and placed in a mortar. The seeds were manually milled by pounding the seeds in the mortar with a mortar pestle to separate the grains from the husk/shaft. The pounded seeds were winnowed cautiously and the grains were separated from the husk. They were all packed and labeled accordingly.

All the samples were grinded, digested and analysed with Atomic Absorption Spectrophotometer (AAS) at $248.3 \mathrm{~nm}$ wavelength to determine the bioavailable $\mathrm{Fe}$ in all the samples.

SARS Soft word was used for the statistical analysis

\section{RESULTS}

\section{Iron (Fe) Content}

In the grain, the Fe concentration was highest in FARO 57 fortified control and lowest in FARO 57 unfortified saline.

Iron $(\mathrm{Fe})$ content in the grain ranges from $41.18 \mathrm{mg}$ (FARO 52 unfortified control and FARO 57 unfortified saline) to $412.50 \mathrm{mg}$ (FARO 57 fortified control) as presented in table 1. 
Table 1: Bioavailable (Fe) in Polished and Unpolished Rice Cultivars used (MG/G) Treaments

\begin{tabular}{|c|c|c|c|c|c|c|c|}
\hline \multicolumn{4}{|c|}{ Polished } & \multicolumn{4}{|l|}{ Unpolished } \\
\hline $\begin{array}{l}\text { CS } \\
33.01 \\
33.01\end{array}$ & $\begin{array}{l}\mathrm{CS}+\mathrm{Fe} \\
56.86 \\
39.87\end{array}$ & $\begin{array}{l}\text { SS } \\
39.54 \\
35.95\end{array}$ & $\begin{array}{l}\mathrm{SS}+\mathrm{Fe} \\
35.95 \\
43.14\end{array}$ & $\begin{array}{l}\text { CS } \\
49.51 \\
49.51\end{array}$ & $\begin{array}{l}\mathrm{CS}+\mathrm{Fe} \\
85.29 \\
59.80\end{array}$ & $\begin{array}{l}\text { SS } \\
59.31 \\
53.92\end{array}$ & $\begin{array}{l}\mathrm{SS}+\mathrm{Fe} \\
53.92 \\
64.71\end{array}$ \\
\hline $\begin{array}{l}27.45 \\
86.60 \\
40.52\end{array}$ & $\begin{array}{l}35.95 \\
275 . \\
43.14\end{array}$ & $\begin{array}{l}43.46 \\
27.45 \\
31.05\end{array}$ & $\begin{array}{l}49.67 \\
33.70 \\
39.54\end{array}$ & $\begin{array}{l}41.18 \\
129.90 \\
60.78\end{array}$ & $\begin{array}{l}53.92 \\
412.50 \\
64.57\end{array}$ & $\begin{array}{l}65.20 \\
41.18 \\
46.57\end{array}$ & $\begin{array}{l}74.51 \\
50.56 \\
59.31\end{array}$ \\
\hline \multicolumn{8}{|c|}{$\begin{array}{l}\text { LSD }=113.3 \\
\text { SS + Fe: Saline soil + Fe foliar application } \\
\text { CS +Fe: Control soil + Fe foliar application } \\
\text { SS: Saline soil only } \\
\text { CS: Control soil only }\end{array}$} \\
\hline
\end{tabular}

The observed LSDs were significant at 0.05 levels in all treatments LSDs; Saline soil + Fe foliar application (18.58), Control soil + Fe foliar application (49.497), Saline soil only (22.705) and Control soil only (23.249). To authenticate this post hoc test using LSD multiple comparisons was conducted. It was observed that, there was no significant difference at 0.05 level of probability. However, it was two-tailed significant when they were correlated with Pearson's correlation coefficient.

Table 2: Bioavailable Iron (Fe) in Cooked Grains and for Human Body Absorption/USE (mg/g) Treatments

\begin{tabular}{|c|c|c|c|c|c|c|c|}
\hline \multicolumn{3}{|c|}{$\begin{array}{l}\text { Cooked Grains }(92.5 \% \text { of } \\
\text { Fe in Grain) }\end{array}$} & Available & \multicolumn{4}{|c|}{$\begin{array}{l}\text { For Human Body Use ( } 5 \% \text { of Available Fe } \\
\text { in Grain) }\end{array}$} \\
\hline CS & $\mathrm{CS}+\mathrm{Fe}$ & SS & $\mathrm{SS}+\mathrm{Fe}$ & CS & $\mathrm{CS}+\mathrm{Fe}$ & SS & $\mathrm{SS}+\mathrm{Fe}$ \\
\hline 30.53 & 52.60 & 36.57 & 33.25 & 1.53 & 2.63 & 1.83 & 1.66 \\
\hline 30.53 & 36.88 & 33.25 & 39.90 & 1.53 & 1.84 & 1.66 & 2.00 \\
\hline 25.39 & 33.25 & 40.20 & 45.94 & 1.27 & 1.66 & 2.01 & 2.30 \\
\hline 80.11 & 254.38 & 25.39 & 31.17 & 4.01 & 12.72 & 1.27 & 1.56 \\
\hline 37.48 & 39.00 & 28.72 & 36.57 & 1.87 & 2.00 & 1.44 & 1.83 \\
\hline
\end{tabular}

SS + Fe: Saline soil + Fe foliar application

CS +Fe: Control soil + Fe foliar application

SS: Saline soil only

CS: Control soil only 
Hotz and McClafferty, 2007, reported that rice has the ability to retain $90 \%$ to $95 \%$ of Fe after cooking, which means that after cooking, using $92.5 \%$, the amount of $\mathrm{Fe}$ that will be bioavailable in these cultivars used for this study will be as presented in table 2 .

\section{DISCUSSION}

\section{Grain Quality}

The grains from the fortified look darker in colour than the unfortified. The unfortified looks brighter. This suggests that the Fe reduce the brightness of grains.

\section{Salinity Effect on Iron (Fe) Bioavailability}

The Fe content in the grain presented in table 1 range from $41.18 \mathrm{mg} / \mathrm{g}$ (FARO 57 unfortified saline) to $412.50 \mathrm{mg} / \mathrm{g}$ (FARO 57 control fortified). The Fe content in all the cultivars increased. However, the increase was more in the control fortified. The general increase is because of the amount of $\mathrm{Fe}$ that was in the soil. The initial amount of $\mathrm{Fe}$ in the soil before planting was $35.50 \mathrm{~g} / \mathrm{kg}$ (Masuda et al, 2008 and Suzuki et al, 2008). Also, flooding facilitated the high $\mathrm{Fe}$ accumulation and it is the reason; the root has the highest $\mathrm{Fe}$ concentration which corroborate Havlin et al,( 2006) report.

From the study, it was observed that salinity affected the mobility of $\mathrm{Fe}$ in FARO 57 . In the fortified saline condition, the $\mathrm{Fe}$ content in the grain was $50.56 \mathrm{mg} / \mathrm{g}$, while in the fortified control it was $412.50 \mathrm{mg} / \mathrm{g}$. In the unfortified saline, it was $41.18 \mathrm{mg} / \mathrm{g}$ and in the unfortified control, it was $129.90 \mathrm{mg} / \mathrm{g}$. This suggests the effect of saline on Fe mobility in rice plant. It clearly showed that both in the fortified and unfortified, Fe content was always higher in the control, indicating that Fe biofortification using FARO 57 is better under normal/non saline soil.

The study also confirmed that for $\mathrm{Fe}$ biofortification under saline condition, UPIA 3 and FARO 44 are better. This also suggests that UPIA 3 and FARO 44 tolerate salinity to a certain level. FARO 57 under normal soil condition does better than all the other varieties among the 5 varieties used. UPIA 3 is the best among the 5 cultivars because it is not only the amount of $\mathrm{Fe}$ retained by the cultivar but, how the cultivar can improve Fe content and high yield under saline condition and be resistant to disease for judicious utilization of unclaimed mangrove lands for agricultural productivity.

\section{Mobility and Resistance of Fe into Grain}

The percentage of $\mathrm{Fe}$ in the grain under saline condition is less than that under control when fortified by foliar application. But for the unfortified that the plant makes use of the available $\mathrm{Fe}$ in the soil, the degree of $\mathrm{Fe}$ partitioned to the grain was higher in the saline than in the control in FARO 44 and UPIA 3. Though, in FARO 57 the control is still higher than the saline in the unfortified. For IWA 4, in the fortified, saline has a higher amount of Fe partitioned to the grain than in the control. While in the unfortified, the control has a higher quantity of Fe partitioned to the grain than in the saline condition. For FARO 52, the amount of Fe partitioned to the grain is always higher in the saline condition than in the control for both the fortified and the unfortified. The study showed that foliar application of $\mathrm{Fe}$ is more effective in non saline environment. The study also showed that salinity resist mobility of $\mathrm{Fe}$ applied externally from leaf and stem into grains.

\section{Bioavailability Issue on Grain}

According to Hotz and McClafferty (2007), only about two third of bioavailable Fe may be retained after the rice is polished. Hence the available Fe that may be retained in these cultivars used for this study after polishing will be as presented in table 1.

According to Bouis and Welch (2010), 5\% of the total Fe present in the grain is thought to be bioavailable for human body. Hence, from the results above, the bioavailable Fe for human body (5\% of the available $\mathrm{Fe}$ in the grain) will be as presented in table 2 .

Comparing these values to USDA Nutrients Database 2011 , which says that every $100 \mathrm{~g}$ of rice gives $0.80 \mathrm{~g}$ of $\mathrm{Fe}$, these results prove the Fe content in these cultivars to be higher.

The $\mathrm{Fe}$ increases in the grains of the cultivars fortified are comparatively higher than the unfortified, especially comparing the fortified control and unfortified control as in case of FARO 57. These cultivars are high yielding and effective in improving the micronutrient status in human as criteria needed to be confirmed biofortified crop (Bouis and Welch 2010). The use of these cultivars by those in the mangrove region will not only improve the Fe availability status for the people but will also broaden their scope of agriculture and hence increase their income. Greater percent of the inhabitants of these regions are fish farmers. They rely only on fishing to sustain their livelihood because the territory is always submerged with water as water (tide) comes and go on daily basis. Iron biofortified rice also gains immunity to tolerate $\mathrm{Fe}$ toxicity in saline environment. These cultivars will be more effective to generate higher Fe biofortified rice by transgenic method corroborating with Masuda et al (2013) report.

\section{IRON (Fe) BIOFORTIFIED GRAINS AND HUMAN HEALTH}

Biofortified grains will to an extent eliminate or reduce the dilemma of human health. It is estimated that $18 \%$ of women in industrialised countries are anaemic; in the developing world, it rise to $56 \%$ and is a contributory factor to women developing health problems and dying 
during pregnancy and childbirth (WHO, 1992). According Fraser and Cooper 2003, the absorption of $\mathrm{Fe}$ in pregnant women is complex and tends to decrease during the first trimester and then rises throughout the remaining period of the pregnancy and during the first months of puerperium. Iron absorption is also influenced by the bioavailability of iron in the diet. It is estimated that an average of $840-1210 \mathrm{mg}$ of iron needs to be absorbed over the period of pregnancy (Beard, 2000). The demand for absorbed iron increases from $0.8 \mathrm{mg} /$ day in early pregnancy to $6 \mathrm{mg} / \mathrm{day}$ in late pregnancy owing to the increase in maternal $\mathrm{Hb}$, and in oxygen consumption by the mother and the foetus, foetal growth and deposition of $\mathrm{Fe}$, placental circulation, the replacement of daily loss through stools, urine and skin, the replacement of blood lost at birth and in the postnatal period and lactation (Bothwell, 2000). WHO, 1992 data on the prevalence of anaemia in women suggest that the normal dietary intakes of iron is insufficient to meet the requirement for the majority of women and in 2003, the WHO also estimated that with Fe biofortification in food crops, two billion $\mathrm{Fe}$ deficiency induced anaemia patients could be cured.

Intake of these $\mathrm{Fe}$ biofortified grains will help reduce the cost of pregnancy management especially among those who consume mainly cereals.

\section{CONCLUSION}

With the degree of mineral malnutrition in humans worldwide, biofortification of micronutrients, especially, Fe should be encouraged. Fe rich soil but below toxic levels will facilitate $\mathrm{Fe}$ biofortification in rice. UPIA 3 tolerates salinity more than the other cultivars among the used cultivars. FARO 57 in non saline soil had the best ability to retain $\mathrm{Fe}$ in $\mathrm{Fe}$ biofortification, but it had a lodging mechanism that affected its yield. Salinity affects the intake of $\mathrm{Fe}$ and yield in FARO57. Fe also has slight effect on yield when applied through foliar. It will be better if the different scenarios can be combined to address and overcome iron toxicity effect on $\mathrm{Fe}$ biofortification on saline soil. Biofortification is the panacea to micronutrients malnutrition worldwide.

\section{REFERENCES}

Anonymous, (2007).Global childhood malnutrition. Lancet 367: 1459.

Anonymous, 2008. The Copenhagen ConsensusResults. P.1-6 (verified 21 Dec. 2009). The Copenhagen Consensus Cent., Fredericksburg, Denmark.

Beard, J L, (2000). Effectiveness and strategies of iron supplementation during pregnancy. American Journal of Clinical Nutrition 71: 1288S-1294S

Bothwell, $\mathrm{T} \mathrm{H},(2000)$ Iron requirements in pregnancy and strategies to meet them. American Journal of Clinical Nutrition 72(1): 257S- 264S
Bouis, H. E. and Welch, R. M. (2010).Biofortification- a sustainable agricultural strategy for reducing micro nutrients in the global South. Crop Sc. 50. S20 S32. Doi: 10.2135/crop sc. 2009.

Fraser, D. M and Cooper, M. A (2003).Myles Textbook for midwives. $14^{\text {th }}$ ed. Churchill Livingstone Elsevier Science Limited pg.333.

Hotz, C. and McClafferty, B. (2007).From harvest to health: Challenges for developing biofortified staple foods and determining their impact on micronutrient status. International Food Policy Research Institute, 2033 K Street NW, Washington DC 20006- 1002, USA; email: mcclafferty@cgiar.org

John, H.L., Beaton, J. D., Tisdale, S. L. and Nelson, W. $L$ (2006). Soil fertility and fertilizers $7^{\text {th }}$ ed. PrenticeHall of India private limited, new Delhi-110001 pg 245-254.

Kennedy G., Nantel, G. and Shetty, P.(2003). The scourge of "hidden hunger". Global dimensions of micronutrients deficiencies. Food Nutr. Agric. 32:816

Masuda, H., Kobayashi, T., Ishimaru, Y., Takahashi, M.,Aung. M S.,Nakanishi, H., Mori, S and Nishizawa, N. K, (2008).Increase in iron and zinc concentration in rice grains via the introduction of barley genes involved in phytosiderosphore synthesis. Rice 1, 100-108.

Masuda, H., Kobayashi, T., Ishimaru, Y., Takahashi, M.,Aung. M S.,Nakanishi, H., Mori, S and Nishizawa, N. K, (2013). Iron-biofortification in rice by the introduction of three barley genes participated in mugineic acid biostnthesis with soybean ferritin gene.PLANT SCIENCE doi: 10.3389/fpls.2013.00132

Maziya-Dixon, B. B., Akinyele, I. O., Sanusi, R. A., Oguntona, T. E., Nokoe, S. K. and Harris, E. W. (2006). Vitamin A deficiency is prevalent in children less than 5 years of age in Nigeria. J. Nutr.2006 Aug.136(8) : 2255- 61.

Nelsons and Co Natural world, 2014.Role of Iron in the body. Nelsons and Co Limited, Nelsons House, 83 Parkside, Wimbledon, London SW195LP.

Ortiz-Monasterio, I. J., Palacios- Rojas, N., Meng, E., Pixley, K., Trethrowan, R. and Pena, R. J. (2007). Enhancing the mineral and vitamin content of wheat and maize through plant breeding. J. Cereal sc. 46: 293-307.

Stewarte, A., Max Grimshaw, H., John, A. Parkinson and Christopher, Q., (1974). Chemical Analysis of Ecological Materials.Blackwell Scientific Publications. Oxford London Edinburgh Melbourne

Suzuki, M., Morikawa, K. C., Nakanishi, H., Takahashi, M., Saigusa, M., Mori, S., et al (2008). Transgenic rice lines that include barley genes have increase tolerance to low iron availability in a calcareous paddy soil. Soil Sci. Plant Nutr. 54,77-85.

U.S. Department of Agriculture, Agricultural Research Service. 2011. USDA National Nutrient Database, for Standard Reference, Release 27.Nutrient Data 
Laboratory Home WHO, (1996).Food Security. World Food Summit 1996, page.http://www.ars.usda.gov/ba/bhnrendl. Rome, Italy.

WHO (World Health Organisation) (1992). The WHO and FAO, (2003).Joint WHO/FAO expert prevalence of anaemia in women: a tabulation of consultation on diet, nutrition and the prevention of available information, $2^{\text {nd }}$ edn. WHO Geneva chronic diseases. World Health Organisation, Geneva, Switzerland.

Cite this Article: Ikuli JM, Akonye LA and Efisue AA (2017). Comparative Study of some Cultivars of Rice (Oryza sativa L.) for Iron Fe Biofortification under Saline Condition. Greener Journal of Agricultural Sciences, 7(4): 105-111, http://doi.org/10.15580/GJAS.2017.4.061117073. 